\title{
virMine: Automated detection of viral sequences from complex metagenomic samples
}

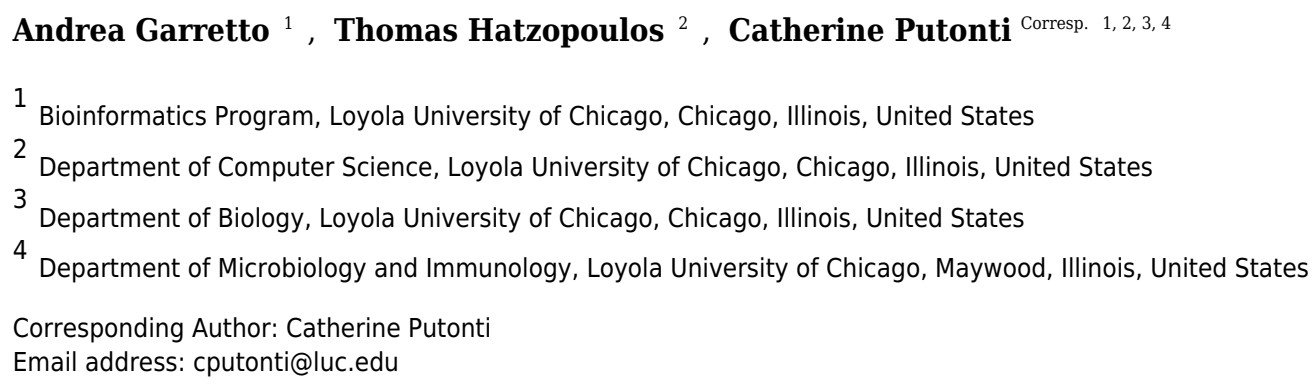

Metagenomics has enabled sequencing of viral communities from a myriad of different environments. Viral metagenomic studies routinely uncover sequences with no recognizable homology to known coding regions or genomes. Nevertheless, complete viral genomes have been constructed directly from complex community metagenomes, often through tedious manual curation. To address this, we developed the software tool virMine to identify viral genomes from raw reads representative of viral or mixed (viral and bacterial) communities. virMine automates sequence read quality control, assembly, and annotation. Researchers can easily refine their search for a specific study system and/or feature(s) of interest. In contrast to other viral genome detection tools that often rely on the recognition of viral signature sequences, virMine is not restricted by the insufficient representation of viral diversity in public data repositories. Rather, viral genomes are identified through an iterative approach, first omitting non-viral sequences. Thus, both relatives of previously characterized viruses and novel species can be detected, including both eukaryotic viruses and bacteriophages. Here we present virMine and its analysis of synthetic communities as well as metagenomic data sets from three distinctly different environments: the gut microbiota, the urinary microbiota, and freshwater viromes. Several new viral genomes were identified and annotated, thus contributing to our understanding of viral genetic diversity in these three environments. 
1 virMine: Automated detection of viral sequences from complex metagenomic samples 2

3 Andrea Garretto ${ }^{1}$, Thomas Hatzopoulos ${ }^{2}$, Catherine Putonti ${ }^{1,2,3,4}$

4

51 Bioinformatics Program, Loyola University Chicago, Chicago, IL USA

62 Department of Computer Science, Loyola University Chicago, Chicago, IL USA

73 Department of Biology, Loyola University Chicago, Chicago, IL USA

84 Department of Microbiology and Immunology, Loyola University Chicago, Maywood, IL 9 USA

11 Corresponding Author:

12 Catherine Putonti

131032 W. Sheridan Road, Chicago, IL, 60660, USA

14 Email address: cputonti@luc.edu

15

16

17 Short title: Detecting viral sequences with virMine 
19

20

21

22

\section{Abstract}

Metagenomics has enabled sequencing of viral communities from a myriad of different environments. Viral metagenomic studies routinely uncover sequences with no recognizable homology to known coding regions or genomes. Nevertheless, complete viral genomes have been constructed directly from complex community metagenomes, often through tedious manual curation. To address this, we developed the software tool virMine to identify viral genomes from raw reads representative of viral or mixed (viral and bacterial) communities. virMine automates sequence read quality control, assembly, and annotation. Researchers can easily refine their search for a specific study system and/or feature(s) of interest. In contrast to other viral genome detection tools that often rely on the recognition of viral signature sequences, virMine is not restricted by the insufficient representation of viral diversity in public data repositories. Rather, viral genomes are identified through an iterative approach, first omitting non-viral sequences. Thus, both relatives of previously characterized viruses and novel species can be detected, including both eukaryotic viruses and bacteriophages. Here we present virMine and its analysis of synthetic communities as well as metagenomic data sets from three distinctly different environments: the gut microbiota, the urinary microbiota, and freshwater viromes. Several new viral genomes were identified and annotated, thus contributing to our understanding of viral genetic diversity in these three environments.

\section{Introduction}

In contrast to eukaryotic and prokaryotic organisms, only a small fraction of viral genomes has been sequenced and characterized. Viral metagenomic studies have been pivotal in increasing our understanding of viral diversity on Earth. Numerous habitats have been explored, such as: marine waters (Breitbart et al. 2002; Yooseph et al. 2007; Hurwitz \& Sullivan 2013; Brum et al. 2015; Coutinho et al. 2017; Zeigler Allen et al. 2017; see review Brum \& Sullivan 2015), soil (Fierer et al. 2007; Zablocki et al. 2014; Adriaenssens et al. 2017; see review Pratama \& van Elsas 2018), freshwaters (López-Bueno et al. 2009, 2015; Roux et al. 2012; see review Bruder et al. 2016), and the human microbiota (e.g., Reyes et al. 2010; Minot et al. 2011, 2013; Pride et al. 2012; Hannigan et al. 2015; Santiago-Rodriguez et al. 2015; Miller-Ensminger et al. 2018; see review Abeles \& Pride 2014). Recent evidence has uncovered that viral members of the human 
50

51

52

53

54

microbiota (see reviews Barr 2017; Keen \& Dantas 2018) and marine environment (see reviews Breitbart et al. 2018) play a more pivotal role than once thought. Regardless of the environment explored, the overwhelming majority of viral sequences produced exhibit no sequence homology to characterized viral species. Even for the well-studied marine viral communities, over $60 \%$ of the coding regions predicted are completely novel (Coutinho et al. 2017).

While metagenomics has been fruitful in identifying gene markers (e.g. 16S rRNA gene) and genomes of uncultivated eukaryotic and prokaryotic species (Hug et al. 2016), surveys of viromes face unique challenges (Bruder et al. 2016; Rose et al. 2016). First, unlike cellular organisms, there is no universally conserved gene in viruses. Viruses span a high degree of genetic diversity and are inherently mosaic (Hatfull 2008). Second, even when sequencing purified virions, sequencing data often includes non-viral (host) DNA. This is further complicated by the fact that viral genomic DNA is often orders of magnitude less abundant than host cells or other organisms in the sample. In addition to the development of experimental procedures for viral metagenomics (e.g., Conceição-Neto et al. 2015; Hayes et al. 2017; Lewandowska et al. 2017), several bioinformatic solutions have been created to aid in detecting viral sequences within mixed communities (e.g., Roux et al. 2015; Hatzopoulos et al. 2016; Yamashita et al. 2016; Ren et al. 2017; Amgarten et al. 2018; see reviews Hurwitz et al. 2017; Nooij et al. 2018). Third, extant viral data repositories do not include sufficient representation of viral species. Thus, tools reliant upon identifying sequence homology, such as those for bacterial metagenome analysis (see review Nayfach \& Pollard 2016), have limited application in virome studies.

The identification of viral genomes from samples containing a single or a few viral species is relatively straight-forward, even in the presence of a large background of non-viral sequences. An example of such an inquiry would be the search for potential viral pathogens from clinical samples. Software tools including VIP (Li Y et al. 2016), VirAmp (Wan et al. 2015), and VirFind (Ho \& Tzanetakis 2014) were designed specifically for such cases. They are, however, limited to the isolation of known viral taxa; complex viral communities pose significantly greater challenges. Typically, one of two approaches is taken. The first approach identifies contigs from metagenomic data sets based upon sequence attributes, e.g., their nucleotide usage profiles (Ren et al. 2017), and/or contig coverage (see reviews Sharon \& Banfield 2013; Garza \& Dutilh 2015; Sangwan et al. 2016). The second, more frequently pursued method, relies largely on recognizable homologies to known viral sequences, e.g. Phage Eco-Locator (Aziz et al. 2011), VIROME (Wommack et al. 
81 2012), MetaVir (Roux et al. 2014), VirSorter (Roux et al. 2015), MetaPhinder (Jurtz et al. 2016), 82 VirusSeeker (Zhao et al. 2017), and FastViromeExplorer (Tithi et al. 2018). The tool MARVEL integrates the two approaches, predicting tailed phage sequences based upon genomic features (gene density and strand shifts) and sequence homologies (Amgarten et al. 2018). Regardless of the approach taken, manual curation and inspection is often a critical step in the process. Several complete viral genomes have been mined from metagenomic data through inspection of sequences based upon their size, coverage, circularity, or sequence homology to annotated viral genes or genes of interest (e.g., Inskeep et al. 2013; Labonté \& Suttle 2013; Dutilh et al. 2014; Smits et al. 2014, 2015; Bellas et al. 2015; Rosario et al. 2015; Zhang et al. 2015; Paez-Espino et al. 2016; Voorhies et al. 2016; Coutinho et al. 2017; Ghai et al. 2017; Watkins et al. 2018). These efforts have uncovered novel viral species, furthering our understanding of genetic diversity in nature.

Here we present virMine for the identification of viral genomes within metagenomic data sets. virMine automates the process of discovery; from raw sequence read quality control through assembly and annotation. virMine incorporates a variety of publicly available tools and userdefined criteria. In contrast to previous bioinformatic tools which search for viral "signatures" based on our limited knowledge of viral diversity on Earth, virMine takes advantage of the wealth of sequence data available for cellular organisms. Thus, viral (bacteriophage and eukaryotic virus) discovery is conducted through the process of excluding what we know not to be viral. Those sequences which are not "non-viral" (i.e., putative viral sequences) are then compared to a database of viral sequences. This comparison distinguishes putative viral sequences similar to known viral sequences and those which may represent novel viruses for downstream analyses. A beta version of this tool was used to isolate viral sequences from urinary metagenome data sets (Garretto et al. 2018). Here we illustrate the utility of this tool using four case-studies: synthetic data sets, gut microbiomes, urinary viromes, and freshwater viromes, resulting in the identification of new strains of known viruses as well as novel viral genomes.

\section{Materials \& Methods}

\section{Pipeline Development}

The pipeline integrates existing tools as well as new algorithms using Python and the BioPython library (Cock et al. 2009). Figure 1 depicts the process employed by virMine. A key aspect of the 
112 tool is its flexibility; it was designed to be modular, allowing users to access functionality

113 individually or execute the full pipeline. While several methods have been incorporated in this 114 release (Table 1), new tools can be added easily. Furthermore, to facilitate targeted analyses, 115 filtration options and customization is available for users without any programming expertise.

116 Users can supply either raw Illumina sequencing reads (single-end or paired-end) or 117 assembled contigs/scaffolds. In the case in which reads are supplied, the raw sequencing data is 118 evaluated using the quality control tool Sickle (https://github.com/najoshi/sickle). Reads are 119 trimmed, generating high quality data for assembly. Presently, the pipeline performs assembly by 120 one of three methods: SPAdes (Bankevich et al. 2012), metaSPAdes (Nurk et al. 2017), and 121 MEGAHIT (Li D et al. 2016). These assemblers were selected as they include tools better equipped 122 for assembly of low complexity samples (SPAdes) and those developed for complex metagenomes 123 (metaSPAdes and MEGAHIT). In a prior study comparing tools for assembly of phage genomes 124 from single or low complexity samples (Rihtman et al. 2016), the SPAdes assembler (Bankevich 125 et al. 2012) outperformed other tools tested. virMine also includes the assembly option "all3." This 126 option assembles the reads using SPAdes, metaSPAdes, and MEGAHIT and selects the assembly 127 with the highest $N_{50}$ score for downstream analysis. The virMine command line includes a flag for 128 the user to specify the number of threads to be used during assembly to best utilize multi-core 129 resources.

Next, virMine includes several options for the user to filter the assembled contigs. This can include minimum and/or maximum contig length, minimum contig coverage, and presence of genes or sequences (such as CRISPR spacer sequences) of interest. Coverage is calculated by remapping the original reads to the contigs, and the per contig coverage is calculated via BBMap (https://sourceforge.net/projects/bbmap/). Coverage is not reported if this option is not selected. Alternatively, when SPAdes (Bankevich et al. 2012) or metaSPAdes (Nurk et al. 2017) is used for assembly, users can select to use the SPAdes "cov" value as a filter. Users can also provide FASTA format sequences of interest (e.g., gene sequences encoding for a specific functionality); contigs are then queried against this data set using blastx. Results with a bitscore $>50$ are considered real hits and only contigs containing these hits will be considered further. Any or all of these filters can be selected by the user. Furthermore, the order in which they are specified by the user determines the order in which the filters are applied. 
In Step 3, coding regions are predicted for each contig. Open reading frame (ORF)

143

144

145

146

147

148

149

150

151

152

153

154

155

156

157

158

159

160

161

162

163

164

165

166

167

168

169

170

171

172

prediction is conducted using the tool GLIMMER (Delcher et al. 1999). Coding regions are predicted using a modified GLIMMER script (available through our GitHub repository), trained to accommodate characteristics of viral genes, e.g. overlapping genes (Chirico et al. 2010) and short coding regions.

In the final step, each predicted ORF is compared to two databases - a collection of nonviral sequences and a collection of known viral sequences. These two databases can be manually curated data collections or obtained from public repositories. While the GitHub repository for virMine includes a script to generate databases from NCBI's RefSeq collection, any multi-fasta file of amino acid sequences can be used to create these databases; the user need only supply the multi-fasta files. Comparisons against these two databases are facilitated via the BLAST + application (Camacho et al. 2008). Users can select to use either a blastp (protein query) or blastx (translated nucleotide) query. While blastx is more exhaustive, blastp is more expedient. Again, the threads flag is used here to expedite these comparisons. All hits are reported from both databases; the bitscores for each ORF's hits to the two databases are compared, and the ORF is called "viral" or "non-viral" based upon the hit with the greater bitscore. Contigs with more "viral" calls are predicted as viral and are written to file ("viral_contigs.fasta"), as are their ORF predictions and BLAST (either blastx or blastp) results. Contigs containing ORFs with no recognizable sequence homology to the viral database or non-viral database are classified as "unknown". These putative viral contigs ("unkn_contigs.fasta") and their ORF predictions are also written to file, as these sequences may represent truly novel species.

\section{Tool Availability}

virMine is available through a Docker image at https://github.com/thatzopoulos/virMine; Docker builds the necessary environment. This repository also includes scripts for generating curated viral and bacterial databases from GenBank. The user can save the contents of their run locally, as well as supply their own input files prior to the building of the environment, by following the steps listed in the GitHub repository. This pipeline can be run on any system supporting Docker (https://www.docker.com/). Development and testing were conducted on the Ubuntu and MacOSX operating systems. 
173 Data Sets

174 The pipeline includes two databases for distinguishing between non-viral and viral sequences. Two

175 data sets were created for our proof-of-concept work. The viral database includes amino acid 176 sequences from all RefSeq (O'Leary et al. 2016) viral genomes and can be retrieved directly online 177 at ftp://ftp.ncbi.nlm.nih.gov/genomes/Viruses/all.faa.tar.gz. This data set includes both eukaryotic 178 viruses and phages. The non-viral data set used for our proof-of-concept work was created using 179 the bacterial COGs collection (Galperin et al. 2015), excluding coding sequences in the category $180 \mathrm{X}$ of phage-derived proteins, transposases, and other mobilome components. The GitHub 181 repository for virMine includes a script to create these two databases.

182 For the proof-of-concept studies presented in the results, four data sets were used. The first 183 is a synthetic data set for benchmarking purposes. Sequencing read sets for a single "non-viral" 184 sequence (Pseudomonas aeruginosa UW4 (NC_019670.1)) and a single viral sequence 185 (Pseudomonas phage PB1 (NC_011810.1)) were created at various "concentrations" using the tool 186 MetaSim (Richter et al. 2008). These synthetic data sets were made both with and without 187 mutations introduced. (Mutations were introduced using the evolve function in which the 188 parameters "number of leaves (Yule-Harding Tree)" and "Jukes-Cantor Model Alpha" were set to 189 190 the defaults 100 and 0.0010 , respectively.) Raw sequencing reads were also obtained from five different studies including the gut microbiota (Qin et al. 2010; Reyes et al. 2010), the urinary microbiota (Santiago-Rodriguez et al. 2015), and freshwater viromes (Sible et al. 2010; Skvortsov et al. 2016). Table 2 summarizes these data sets; details regarding the urls for these data sets can 193 be found in Supplemental File 1.

Local BLAST searches of contigs were conducted using the complete nr/nt database (downloaded 6/24/2017). Remote BLAST queries were conducted through the NCBI website. Genome annotations were generated using RAST (Aziz et al. 2008), previously used for phage genome annotations (McNair et al. 2018). Contig mapping to complete genome sequences was performed using Bowtie2 (Langmead \& Salzberg 2012).

\section{Results \& Discussion}

202

virMine is a single tool to perform raw read quality control, assembly, annotation, and analysis 203

(Figure 1). The virMine tool, as described in the Methods, identifies viral sequences and putative 
204 viral sequences in metagenomic data sets by harnessing the wealth of non-viral sequence data

205 available; contigs are scored based upon their similarity to non-viral and viral sequences. Four case

206 studies were derived to test the efficacy of the virMine software tool, including one synthetic data

207 set and three different environmental samples from the gut, urine, and freshwaters.

208

209 Case Study 1: Synthetic Data Sets

210 Sequencing reads were generated using the tool MetaSim (Richter et al. 2008) using a sample

211 “non-viral” genome sequence, Pseudomonas aeruginosa UW4 genome [GenBank: NC_019670],

212 and a viral genome sequence, Pseudomonas phage PB1 [GenBank: NC_011810]. Eleven synthetic

213 data sets were created in which $0 \%$ through 100\% (increments of 10\%) of the data set comprised

214 of "reads" from the phage genome sequence. Each synthetic data set was processed independently;

215 assemblies were generated using SPAdes (Bankevich et al. 2012) with the requirement that the

216 coverage (-cov flag) be greater than or equal to three.

217 Figure 2 summarizes the results of the analyses. When $50 \%$ or more of the reads were

218 from the PB1 genome, the complete PB1 genome could be reconstructed. As the $N_{50}$ scores for

219 each of the runs show, the length of the virMine assembled viral genome exceeds that of the PB1

220 genome $(65,764 \mathrm{bps})$; this is a residual of the direct terminal repeats (DTRs) in the PB1 sequence.

221 The presence of DTRs frequently leads to "wrap-around" reads contained within the genome

222 assembly (Merrill et al. 2016). Each contig that did not correspond with the PB1 genome, including

223 those identified within the 0\% PB1 genome data set, was further examined via local blastn against

224 the nr/nt database (Supplemental File 2). As Figure 2 shows, even for the synthetic data set with

225 no reads from the PB1 genome, two contigs were predicted by virMine to be viral. We further

226 investigated these contigs, 1021 and 1007bp in length; the first contig is homologous to an IS3

227 family transposase [GenBank: AFY17357] and an IS110 family transposase [GenBank:

228 AFY17680], respectively. As these transposases are assigned COG id numbers within the category

$229 \mathrm{X}$, they were excluded from the non-viral database and thus not recognized as non-viral.

230 Transposases are abundant in nature and have been found within phage genomes (Aziz et al. 2010).

231 MetaSim (Richter et al. 2008) was used again to produce synthetic data sets for the $P$.

232 aeruginosa and Pseudomonas phage PB1, this time introducing mutation (population-based

233 random mutator; see Methods). As shown in Supplemental File 2, the assemblies produced were

234 significantly more fragmented (lower $N_{50}$ scores); even when all reads were derived from the PB1 
235 genome sequence, the $N_{50}$ score was only 762 bp (in contrast to the single, full genome contig

236 produced with the read sets generated without mutation). It is interesting to note that while the 237 assemblers could not reconstruct the full genome or longer contigs, virMine still classified contigs

238 as viral and subsequent blastn analyses were able to resolve the origin of the sequence.

239

240

241

242

243

244

245

246

247

248

249

250

251

252

253

254

255

256

257

258

259

260

261

262

263

264

265

\section{Case Study 2: Gut Microbiomes}

Two separate gut microbiome data sets were examined (Table 2). The first includes the sequence data sets that were examined leading to the discovery of the crAssphage genome sequence $(97,065$ bp) (Dutilh et al. 2014): the data set of Reyes et al. (2010). The crAssphage has since been detected in raw sewage and sewage impacted water samples (Stachler et al. 2017). Similar to the methods employed in the discovery of the crAssphage, both the sequence data sets of the individual samples and an aggregate of all reads were assembled by virMine using SPAdes (Bankevich et al. 2012). Numerous sequences predicted to be viral were identified within the individual samples (727 total) and the aggregate data set (927 total) (Supplemental File 2). Local blastn analyses identified many of these contigs as representative of transposases and integrases. The abundance of transposase sequences within metagenomic sequences has previously been noted for a variety of environments (Brazelton \& Baross 2009; Aziz et al. 2010; Vigil-Stenman et al. 2017). We compared the contigs identified as viral to the crAssphage genome sequence [GenBank: JQ995537]. 94.88\% of the crAssphage genome was represented in 372 contigs identified as viral sequences. Coverage of the crAssphage increases when contigs classified as unknown are considered: $98.32 \%$ of the genome is represented in 613 contigs (Figure 3). Several other complete viral genomes were also identified by virMine including a Gokushovirus and Microvirus exhibiting homology to the sequenced genomes of Gokushovirus WZ-2015a [GenBank: KT264754] and the newly discovered Microviridae sp. isolate ctci6 [GenBank: MH617627]. It is worth noting that this Microviridae genome was not included in our viral database and exhibits no significant homology to other records in the current BLAST Nucleotide collection.

The second gut microbiota data set was a subset of the fecal samples from 124 European individuals (Qin et al. 2010). Most of this data set is bacterial in origin, with only $0.1 \%$ predicted by the authors of the study to be of eukaryotic and viral origin. Using virMine we also found that most of the sequences were likely bacterial (Supplemental File 2). However, we found that the prediction of the study's authors underestimated the viral population; 1.31 to $38.43 \%$ of the 
266

267

268

269

270

271

272

273

274

275

276

277

278

279

280

281

282

283

284

285

286

287

288

289

290

291

292

293

294

295

296

assembled contigs were predicted by virMine to be viral in origin. We hypothesize that this discrepancy may be due to prophage sequences. As our previous analysis with the beta version of the software showed, virMine can identify prophage sequences within bacterial genome contigs as well as extrachromosomal viruses (Garretto et al. 2018). This underestimate may also be a result of our increased knowledge of viral diversity; the number of viral sequences in GenBank has tripled since the study of Qin et al. (2010) was published. The summary of our analysis of the 55 samples from this study are listed in Supplemental File 2. In total 28,673 and 311,457 contigs were categorized as viral and unknown, respectively.

\section{Case Study 3: Urinary Viromes}

Ten data sets, collected from individuals with urinary tract infections (Santiago-Rodriguez et al. 2015), were selected for analysis. In contrast to the gut microbiomes examined in Case Study 2, these samples were prepared such that the majority (if not all) of the sequenced DNA was representative of the viral fraction (Santiago-Rodriguez et al. 2015). Exploration of the urinary virome has only recently begun. Of the few viral metagenomic studies of the urinary microbiota (Santiago-Rodriguez et al. 2015; Rani et al. 2016; Thannesberger et al. 2017; Garretto et al. 2018; Miller-Ensminger et al. 2018; Moustafa et al. 2018), most of the identifiable sequences are similar to characterized phage sequences. Nevertheless, the vast majority of contigs exhibit no identifiable homology to sequence databases. As summarized in Supplemental File 2, each sample consisted of more contigs in the "unknown" category than the "viral" category. We selected the larger contigs ( $>5000 \mathrm{bp})$ that were predicted as viral and queried them via megablast against the $\mathrm{nr} / \mathrm{nt}$ database online. Table 3 presents the results of this search. virMine identified similarities to annotated prophage sequences (indicated by asterisks), extrachromosomal phages, and eukaryotic viral sequences.

\section{Case Study 4: Freshwater Viromes}

Two freshwater viromes were considered. The first includes four samples from the Lake Michigan nearshore waters, collected by our group (Sible et al. 2015; Watkins et al. 2016). The second includes samples taken from Lough Neagh, the largest freshwater lake in Ireland (Skvortsov et al. 2016). The summary statistics for our analysis are included in Supplemental File 2. Sequences predicted to be viral within the four Lake Michigan data sets were inspected. Hits to known viral 
297 sequences varied between samples; in total, sequence homologies were detected to 834 different 298 phage $(n=425)$ and eukaryotic viruses $(n=409)$. Figure 4 illustrates the species, predominantly 299 phages, with the most hits. From the Lough Neagh data set, nine contigs were identified by virMine

300

301

302

303

304

305

306

307

308

309

310

311

312

313

314

315

316

317

318

319

320

321

322

323

324

325

326

327 as viral and had a length greater than $40 \mathrm{Kbp}$. In the study introducing this data set (Skvortsov et al. 2016), only five contigs were produced meeting this length threshold. (The IDBA-UD assembler (Peng et al. 2012) was used in the original analysis of this data set (Skvortsov et al. 2016).) Each contig was submitted to RAST (Aziz et al. 2008) for annotation and each was found to contain phage-related genes (Supplemental File 3), suggesting that the contigs represented complete or partial phage genomes. We next queried each contig against the $\mathrm{nr} / \mathrm{nt}$ database via blastn identifying only modest sequence homology to bacterial, phage, and uncultured viral isolate sequences (Table 4). These contigs thus represent likely novel viral sequences.

\section{virMine Performance}

To assess the performance of virMine, the freshwater data sets were also examined using the viral sequence identification tool VirSorter (v. 1.0.3) (Roux et al. 2015). For all five data sets, we found that very few contigs were predicted as viral by both tools. For instance, in the Lough Neagh data set, VirSorter only identified (a category 2 prediction) one of the nine virMine contigs (length > $40 \mathrm{Kbp}$ ). This prompted our manual inspection of these results. Herein we present the results for one of the samples from Lake Michigan (SRA Accession number SRR1296481), representative of what we found in all sets. virMine predicted 60 of the 1518 assembled contigs as viral. VirSorter predicted only 20 viral sequences (two category 1; five category 2; six category 3; no category 4; four category 5; and three category 6). Only two sequences were predicted by both tools. As virMine was designed for identifying viral contigs and VirSorter was designed to identify both viral contigs (categories 1-3) and prophages (categories 4-6), it is not surprising that both contigs detected by the two tools were VirSorter category 2 sequences. (While virMine can identify prophages, as was shown previously (Garretto et al. 2018), it will not identify prophages within large bacterial contigs.) BLAST queries to the $\mathrm{nr} / \mathrm{nt}$ database of the sequences uniquely identified by virMine and VirSorter are listed in Supplemental File 3; many of these predicted sequences exhibited homology to bacterial RNAs (rRNA and tRNA). Only four additional sequences (two predicted by virMine and two predicted by VirSorter) exhibited homology to genes/sequences annotated as phage. 
Our comparison of virMine to VirSorter highlights the importance of manual inspection of

329

330

331

332

333

334

335

336

337

338

339

340

341

342

343

344

345

346

347

348

349

350

351

352

353

354

355

356

357

358

results. In contrast to VirSorter and, e.g., VirFinder, virMine not only predicts viral sequences but also reports the blast results of these sequences. This aids in the manual inspection of the virMine predictions. It is important to note that our comparison here, however, is not entirely an equivalent assessment: VirSorter relies on a different sequence database than virMine. As described in Roux et al. (2016), two reference databases are used by VirSorter. These databases have been updated to version 2 since the time of its publication, and details regarding this update are not readily available. In fact, the viral databases used by existing tools varies greatly. VirSorter and MARVEL restrict their viral database to phages, all phages and dsDNA phages from the Caudovirales order, respectively. However, virMine includes all viral sequences - phages as well as eukaryotic viruses. As shown in Figure 4, a number of hits to eukaryotic viruses were identified within the Lake Michigan data sets. While VirusSeeker's database is not restricted to phage sequences, as it too contains eukaryotic viral sequences, it is a curated database (last updated August 2016). Currently, MetaPhinder's and MetaVir's databases are also out of date; both were last updated in 2017. virMine's database is entirely controlled by the user and can include all data currently available. Just as virMine allows the user to create their own custom databases, so too does FastViromeExplorer. FastViromeExplorer requires the user to format files for use. In contrast, virMine only necessitates a multi-fasta file which can easily be retrieved from publicly available databases like NCBI and IMG/VR or via user-specific queries of public sequence repositories.

\section{Conclusions}

As highlighted in the recent report of the International Committee on Taxonomy of Viruses (ICTV) Executive Committee, genomes identified from metagenomic data will vastly expand our catalog of viral diversity (Simmonds et al. 2017). Within just the past two years, there has been an explosive growth of the number of uncultivated viral genomes identified within metagenomic data (Roux et al. 2019). Our analysis of complex communities has uncovered numerous novel viral genomes. virMine is capable of identifying both prophages in contigs and viral sequences. In contrast to other tools that rely solely on viral sequence availability, virMine makes use of a far larger, more comprehensive data set - non-viral sequences. Furthermore, the entire process 
359 from raw sequence quality control through analysis is packaged into a single tool providing a

360 "consensus" solution for viral genome discovery (Dutilh et al. 2017). Manual inspection of

361 virMine results can thus lead to the identification of viral sequences resembling known viruses as

362 well as novel viral strains. As exemplified here, virMine can be used to identify viruses in any

363 niche and thus further our understanding of this vast reservoir of genetic diversity.

364

365

366

Acknowledgements

367

368

369

370

371

372

373

374

375

376

377

378

379

380

381

382

383

384

385

386

387

388

The authors would like to thank Ms. Ally Miley for conversations during the development of this tool and Dr. Jason Shapiro for his feedback on earlier versions of the manuscript.

\section{References}

Abeles SR., Pride DT. 2014. Molecular bases and role of viruses in the human microbiome. Journal of Molecular Biology 426:3892-3906. DOI: 10.1016/j.jmb.2014.07.002.

Adriaenssens EM., Kramer R., Van Goethem MW., Makhalanyane TP., Hogg I., Cowan DA. 2017. Environmental drivers of viral community composition in Antarctic soils identified by viromics. Microbiome 5:83. DOI: 10.1186/s40168-017-0301-7.

Amgarten D, Braga LPP, da Silva AM, Setubal JC. 2018. MARVEL, a Tool for Prediction of Bacteriophage Sequences in Metagenomic Bins. Front Genet 9:304. DOI: 10.3389/fgene.2018.00304.

Aziz RK., Bartels D., Best AA., DeJongh M., Disz T., Edwards RA., Formsma K., Gerdes S., Glass EM., Kubal M., Meyer F., Olsen GJ., Olson R., Osterman AL., Overbeek RA., McNeil LK., Paarmann D., Paczian T., Parrello B., Pusch GD., Reich C., Stevens R., Vassieva O., Vonstein V., Wilke A., Zagnitko O. 2008. The RAST Server: rapid annotations using subsystems technology. BMC Genomics 9:75. DOI: $\underline{10.1186 / 1471-}$ 2164-9-75.

Aziz RK., Breitbart M., Edwards RA. 2010. Transposases are the most abundant, most ubiquitous genes in nature. Nucleic Acids Research 38:4207-4217. DOI: $10.1093 / \mathrm{nar} / \mathrm{gkq} 140$. 
389 390

391

392

393

394

395

396

397

398

399

400

401

402

403

404

405

406

407

408

409

410

411

412

413

414

415

416

417

418

419

Aziz RK., Dwivedi B., Breitbart M., Edwards RA. 2011. Phage Eco-Locator: a web tool for visualization and analysis of phage genomes in metagenomic data sets. $B M C$ Bioinformatics 12:A9. DOI: 10.1186/1471-2105-12-S7-A9.

Bankevich A., Nurk S., Antipov D., Gurevich AA., Dvorkin M., Kulikov AS., Lesin VM., Nikolenko SI., Pham S., Prjibelski AD., Pyshkin AV., Sirotkin AV., Vyahhi N., Tesler G., Alekseyev MA., Pevzner PA. 2012. SPAdes: a new genome assembly algorithm and its applications to single-cell sequencing. Journal of Computational Biology: A Journal of Computational Molecular Cell Biology 19:455-477. DOI: 10.1089/cmb.2012.0021.

Barr JJ. 2017. A bacteriophages journey through the human body. Immunological Reviews 279:106-122. DOI: 10.1111/imr.12565.

Bellas CM., Anesio AM., Barker G. 2015. Analysis of virus genomes from glacial environments reveals novel virus groups with unusual host interactions. Frontiers in Microbiology 6. DOI: $\underline{10.3389 / \mathrm{fmicb} .2015 .00656 .}$

Brazelton WJ., Baross JA. 2009. Abundant transposases encoded by the metagenome of a hydrothermal chimney biofilm. The ISME journal 3:1420-1424. DOI: 10.1038/ismej.2009.79.

Breitbart M., Bonnain C., Malki K., Sawaya NA. 2018. Phage puppet masters of the marine microbial realm. Nature Microbiology 3:754-766. DOI: 10.1038/s41564-018-0166-y.

Breitbart M., Salamon P., Andresen B., Mahaffy JM., Segall AM., Mead D., Azam F., Rohwer F. 2002. Genomic analysis of uncultured marine viral communities. Proceedings of the National Academy of Sciences of the United States of America 99:14250-14255. DOI: 10.1073/pnas.202488399.

Bruder K., Malki K., Cooper A., Sible E., Shapiro JW., Watkins SC., Putonti C. 2016. Freshwater Metaviromics and Bacteriophages: A Current Assessment of the State of the Art in Relation to Bioinformatic Challenges. Evolutionary Bioinformatics Online 12:2533. DOI: $10.4137 / \mathrm{EBO}$. S38549.

Brum JR., Ignacio-Espinoza JC., Roux S., Doulcier G., Acinas SG., Alberti A., Chaffron S., Cruaud C., de Vargas C., Gasol JM., Gorsky G., Gregory AC., Guidi L., Hingamp P., Iudicone D., Not F., Ogata H., Pesant S., Poulos BT., Schwenck SM., Speich S., Dimier C., Kandels-Lewis S., Picheral M., Searson S., Tara Oceans Coordinators, Bork P., Bowler C., Sunagawa S., Wincker P., Karsenti E., Sullivan MB. 2015. Ocean plankton. 
420

421

422

423

424

425

426

427

428

429

430

431

432

433

434

435

436

437

438

439

440

441

442

443

444

445

446

447

448

449

Patterns and ecological drivers of ocean viral communities. Science (New York, N.Y.) 348:1261498. DOI: $10.1126 /$ science.1261498.

Brum JR., Sullivan MB. 2015. Rising to the challenge: accelerated pace of discovery transforms marine virology. Nature Reviews Microbiology 13:147-159. DOI: $\underline{10.1038 / \text { nrmicro3404. }}$

Camacho C, Coulouris G, Avagyan V, Ma N, Papadopoulos J, Bealer K, Madden TL. 2009. BLAST+: architecture and applications. BMC Bioinformatics 10:421. DOI: 10.1186/1471-2105-10-421.

Chirico N, Vianelli A, Belshaw R. 2010. Why genes overlap in viruses. Proceedings. Biological Sciences 277:3809-3817. DOI: 10.1098/rspb.2010.1052.

Cock PJA., Antao T., Chang JT., Chapman BA., Cox CJ., Dalke A., Friedberg I., Hamelryck T., Kauff F., Wilczynski B., de Hoon MJL. 2009. Biopython: freely available Python tools for computational molecular biology and bioinformatics. Bioinformatics 25:1422-1423. DOI: $10.1093 /$ bioinformatics/btp163.

Conceição-Neto N., Zeller M., Lefrère H., De Bruyn P., Beller L., Deboutte W., Yinda CK., Lavigne R., Maes P., Van Ranst M., Heylen E., Matthijnssens J. 2015. Modular approach to customise sample preparation procedures for viral metagenomics: a reproducible protocol for virome analysis. Scientific Reports 5:16532. DOI: 10.1038/srep16532.

Coutinho FH., Silveira CB., Gregoracci GB., Thompson CC., Edwards RA., Brussaard CPD., Dutilh BE., Thompson FL. 2017. Marine viruses discovered via metagenomics shed light on viral strategies throughout the oceans. Nature Communications 8:15955. DOI: $10.1038 /$ ncomms 15955.

Delcher AL, Harmon D, Kasif S, White O, Salzberg SL. 1999. Improved microbial gene identification with GLIMMER. Nucleic Acids Research 27:4636-4641.

Dutilh BE., Cassman N., McNair K., Sanchez SE., Silva GGZ., Boling L., Barr JJ., Speth DR., Seguritan V., Aziz RK., Felts B., Dinsdale EA., Mokili JL., Edwards RA. 2014. A highly abundant bacteriophage discovered in the unknown sequences of human faecal metagenomes. Nature Communications 5:4498. DOI: 10.1038/ncomms5498.

Dutilh BE., Reyes A., Hall RJ., Whiteson KL. 2017. Editorial: Virus Discovery by Metagenomics: The (Im)possibilities. Frontiers in Microbiology 8:1710. DOI: $\underline{10.3389 / \text { fmicb.2017.01710. }}$ 
450 Fierer N., Breitbart M., Nulton J., Salamon P., Lozupone C., Jones R., Robeson M., Edwards

451

452

453

454

455

456

457

458

459

460

461

462

463

464

465

466

467

468

469

470

471

472

473

474

475

476

477

478

479

RA., Felts B., Rayhawk S., Knight R., Rohwer F., Jackson RB. 2007. Metagenomic and small-subunit rRNA analyses reveal the genetic diversity of bacteria, archaea, fungi, and viruses in soil. Applied and Environmental Microbiology 73:7059-7066. DOI: 10.1128/AEM.00358-07.

Galperin MY., Makarova KS., Wolf YI., Koonin EV. 2015. Expanded microbial genome coverage and improved protein family annotation in the COG database. Nucleic Acids Research 43:D261-269. DOI: 10.1093/nar/gku1223.

Garretto A., Thomas-White K., Wolfe AJ., Putonti C. 2018. Detecting viral genomes in the female urinary microbiome. The Journal of General Virology 99:1141-1146. DOI: 10.1099/jgv.0.001097.

Garza DR., Dutilh BE. 2015. From cultured to uncultured genome sequences: metagenomics and modeling microbial ecosystems. Cellular and molecular life sciences: CMLS 72:42874308. DOI: $10.1007 / \mathrm{s} 00018-015-2004-1$.

Ghai R., Mehrshad M., Mizuno CM., Rodriguez-Valera F. 2017. Metagenomic recovery of phage genomes of uncultured freshwater actinobacteria. The ISME Journal 11:304-308. DOI: $10.1038 /$ ismej.2016.110.

Hannigan GD., Meisel JS., Tyldsley AS., Zheng Q., Hodkinson BP., SanMiguel AJ., Minot S., Bushman FD., Grice EA. 2015. The human skin double-stranded DNA virome: topographical and temporal diversity, genetic enrichment, and dynamic associations with the host microbiome. mBio 6:e01578-01515. DOI: $10.1128 / \mathrm{mBio} .01578-15$.

Hatfull GF. 2008. Bacteriophage genomics. Current Opinion in Microbiology 11:447-453. DOI: 10.1016/j.mib.2008.09.004.

Hatzopoulos T., Watkins SC., Putonti C. 2016. PhagePhisher: a pipeline for the discovery of covert viral sequences in complex genomic datasets. Microbial Genomics 2:e000053. DOI: $\underline{10.1099 / \text { mgen.0.000053. }}$

Hayes S., Mahony J., Nauta A., van Sinderen D. 2017. Metagenomic Approaches to Assess Bacteriophages in Various Environmental Niches. Viruses 9. DOI: 10.3390/v9060127.

Ho T., Tzanetakis IE. 2014. Development of a virus detection and discovery pipeline using next generation sequencing. Virology 471-473:54-60. DOI: 10.1016/j.virol.2014.09.019. 
480

481

482

483

484

485

486

487

488

489

490

491

492

493

494

495

496

497

498

499

500

501

502

503

504

505

506

507

508

509

Hug LA., Baker BJ., Anantharaman K., Brown CT., Probst AJ., Castelle CJ., Butterfield CN., Hernsdorf AW., Amano Y., Ise K., Suzuki Y., Dudek N., Relman DA., Finstad KM., Amundson R., Thomas BC., Banfield JF. 2016. A new view of the tree of life. Nature Microbiology 1:16048. DOI: 10.1038/nmicrobiol.2016.48.

Hurwitz BL, Ponsero A, Thornton J, U’Ren JM. 2018. Phage hunters: Computational strategies for finding phages in large-scale 'omics datasets. Virus Research 244:110-115. DOI: 10.1016/j.virusres.2017.10.019.

Hurwitz BL., Sullivan MB. 2013. The Pacific Ocean virome (POV): a marine viral metagenomic dataset and associated protein clusters for quantitative viral ecology. PloS One 8:e57355. DOI: $10.1371 /$ journal.pone.0057355.

Inskeep WP., Jay ZJ., Herrgard MJ., Kozubal MA., Rusch DB., Tringe SG., Macur RE., Jennings R deM., Boyd ES., Spear JR., Roberto FF. 2013. Phylogenetic and functional analysis of metagenome sequence from high-temperature archaeal habitats demonstrate linkages between metabolic potential and geochemistry. Frontiers in Microbiology 4:95. DOI: $10.3389 /$ fmicb.2013.00095.

Jurtz VI., Villarroel J., Lund O., Voldby Larsen M., Nielsen M. 2016. MetaPhinder-Identifying bacteriophage sequences in metagenomic data sets. PloS One 11:e0163111. DOI: 10.1371/journal.pone.0163111.

Keen EC., Dantas G. 2018. Close Encounters of Three Kinds: Bacteriophages, Commensal Bacteria, and Host Immunity. Trends in Microbiology. DOI: 10.1016/j.tim.2018.05.009.

Labonté JM., Suttle CA. 2013. Previously unknown and highly divergent ssDNA viruses populate the oceans. The ISME Journal 7:2169-2177. DOI: 10.1038/ismej.2013.110.

Langmead B., Salzberg SL. 2012. Fast gapped-read alignment with Bowtie 2. Nature Methods 9:357-359. DOI: $10.1038 /$ nmeth.1923.

Lewandowska DW., Zagordi O., Geissberger F-D., Kufner V., Schmutz S., Böni J., Metzner KJ., Trkola A., Huber M. 2017. Optimization and validation of sample preparation for metagenomic sequencing of viruses in clinical samples. Microbiome 5:94. DOI: 10.1186/s40168-017-0317-Z.

Li D., Luo R., Liu C-M., Leung C-M., Ting H-F., Sadakane K., Yamashita H., Lam T-W. 2016. MEGAHIT v1.0: A fast and scalable metagenome assembler driven by advanced 
510

511

512

513

514

515

516

517

518

519

520

521

522

523

524

525

526

527

528

529

530

531

532

533

534

535

536

537

538

539

540

methodologies and community practices. Methods (San Diego, Calif.) 102:3-11. DOI: 10.1016/j.ymeth.2016.02.020.

Li Y., Wang H., Nie K., Zhang C., Zhang Y., Wang J., Niu P., Ma X. 2016. VIP: an integrated pipeline for metagenomics of virus identification and discovery. Scientific Reports 6:23774. DOI: $10.1038 / \operatorname{srep} 23774$.

López-Bueno A., Rastrojo A., Peiró R., Arenas M., Alcamí A. 2015. Ecological connectivity shapes quasispecies structure of RNA viruses in an Antarctic lake. Molecular Ecology 24:4812-4825. DOI: $10.1111 /$ mec.13321.

López-Bueno A., Tamames J., Velázquez D., Moya A., Quesada A., Alcamí A. 2009. High diversity of the viral community from an Antarctic lake. Science (New York, N.Y.) 326:858-861. DOI: 10.1126/science.1179287.

McNair K, Aziz RK, Pusch GD, Overbeek R, Dutilh BE, Edwards R. 2018. Phage Genome Annotation Using the RAST Pipeline. Methods in Molecular Biology (Clifton, N.J.) 1681:231-238. DOI: 10.1007/978-1-4939-7343-9_17.

Merrill BD., Ward AT., Grose JH., Hope S. 2016. Software-based analysis of bacteriophage genomes, physical ends, and packaging strategies. BMC Genomics 17:679. DOI: 10.1186/s12864-016-3018-2.

Miller-Ensminger T, Garretto A, Brenner J, Thomas-White K, Zambom A, Wolfe AJ, Putonti C. 2018. Bacteriophages of the Urinary Microbiome. Journal of Bacteriology 200. DOI: 10.1128/JB.00738-17.

Minot S., Bryson A., Chehoud C., Wu GD., Lewis JD., Bushman FD. 2013. Rapid evolution of the human gut virome. Proceedings of the National Academy of Sciences of the United States of America 110:12450-12455. DOI: 10.1073/pnas.1300833110.

Minot S., Sinha R., Chen J., Li H., Keilbaugh SA., Wu GD., Lewis JD., Bushman FD. 2011. The human gut virome: inter-individual variation and dynamic response to diet. Genome Research 21:1616-1625. DOI: 10.1101/gr.122705.111.

Nayfach S, Pollard KS. 2016. Toward Accurate and Quantitative Comparative Metagenomics. Cell 166:1103-1116. DOI: 10.1016/j.cell.2016.08.007.

Moustafa A., Li W., Singh H., Moncera KJ., Torralba MG., Yu Y., Manuel O., Biggs W., Venter JC., Nelson KE., Pieper R., Telenti A. 2018. Microbial metagenome of urinary tract infection. Scientific Reports 8. DOI: 10.1038/s41598-018-22660-8. 
541 Nooij S., Schmitz D., Vennema H., Kroneman A., Koopmans MPG. 2018. Overview of Virus

542

543

544

545

546

547

548

549

550

551

552

553

554

555

556

557

558

559

560

561

562

563

564

565

566

567

568

569

570

571 Metagenomic Classification Methods and Their Biological Applications. Frontiers in Microbiology 9. DOI: 10.3389/fmicb.2018.00749.

Nurk S., Meleshko D., Korobeynikov A., Pevzner PA. 2017. metaSPAdes: a new versatile metagenomic assembler. Genome Research 27:824-834. DOI: 10.1101/gr.213959.116.

O’Leary NA., Wright MW., Brister JR., Ciufo S., Haddad D., McVeigh R., Rajput B., Robbertse B., Smith-White B., Ako-Adjei D., Astashyn A., Badretdin A., Bao Y., Blinkova O., Brover V., Chetvernin V., Choi J., Cox E., Ermolaeva O., Farrell CM., Goldfarb T., Gupta T., Haft D., Hatcher E., Hlavina W., Joardar VS., Kodali VK., Li W., Maglott D., Masterson P., McGarvey KM., Murphy MR., O’Neill K., Pujar S., Rangwala SH., Rausch D., Riddick LD., Schoch C., Shkeda A., Storz SS., Sun H., Thibaud-Nissen F., Tolstoy I., Tully RE., Vatsan AR., Wallin C., Webb D., Wu W., Landrum MJ., Kimchi A., Tatusova T., DiCuccio M., Kitts P., Murphy TD., Pruitt KD. 2016. Reference sequence (RefSeq) database at NCBI: current status, taxonomic expansion, and functional annotation. Nucleic Acids Research 44:D733-745. DOI: 10.1093/nar/gkv1189.

Paez-Espino D., Eloe-Fadrosh EA., Pavlopoulos GA., Thomas AD., Huntemann M., Mikhailova N., Rubin E., Ivanova NN., Kyrpides NC. 2016. Uncovering Earth's virome. Nature 536:425-430. DOI: 10.1038/nature19094.

Peng Y, Leung HCM, Yiu SM, Chin FYL. 2012. IDBA-UD: a de novo assembler for single-cell and metagenomic sequencing data with highly uneven depth. Bioinformatics (Oxford, England) 28:1420-1428. DOI: 10.1093/bioinformatics/bts174.

Pratama AA., van Elsas JD. 2018. The "Neglected" soil virome - Potential role and impact. Trends in Microbiology. DOI: 10.1016/j.tim.2017.12.004.

Pride DT., Salzman J., Haynes M., Rohwer F., Davis-Long C., White RA., Loomer P., Armitage GC., Relman DA. 2012. Evidence of a robust resident bacteriophage population revealed through analysis of the human salivary virome. The ISME journal 6:915-926. DOI: 10.1038/ismej.2011.169.

Qin J., Li R., Raes J., Arumugam M., Burgdorf KS., Manichanh C., Nielsen T., Pons N., Levenez F., Yamada T., Mende DR., Li J., Xu J., Li S., Li D., Cao J., Wang B., Liang H., Zheng H., Xie Y., Tap J., Lepage P., Bertalan M., Batto J-M., Hansen T., Le Paslier D., Linneberg A., Nielsen HB., Pelletier E., Renault P., Sicheritz-Ponten T., Turner K., Zhu 
572

573

574

575

576

577

578

579

580

581

582

583

584

585

586

587

588

589

590

591

592

593

594

595

596

597

598

599

600

601

602

H., Yu C., Li S., Jian M., Zhou Y., Li Y., Zhang X., Li S., Qin N., Yang H., Wang J., Brunak S., Doré J., Guarner F., Kristiansen K., Pedersen O., Parkhill J., Weissenbach J., MetaHIT Consortium, Bork P., Ehrlich SD., Wang J. 2010. A human gut microbial gene catalogue established by metagenomic sequencing. Nature 464:59-65. DOI: $10.1038 /$ nature08821.

Rani A., Ranjan R., McGee HS., Metwally A., Hajjiri Z., Brennan DC., Finn PW., Perkins DL. 2016. A diverse virome in kidney transplant patients contains multiple viral subtypes with distinct polymorphisms. Scientific Reports 6. DOI: 10.1038/srep33327.

Ren J., Ahlgren NA., Lu YY., Fuhrman JA., Sun F. 2017. VirFinder: a novel k-mer based tool for identifying viral sequences from assembled metagenomic data. Microbiome 5:69. DOI: $\underline{10.1186 / \mathrm{s} 40168-017-0283-5 .}$

Reyes A., Haynes M., Hanson N., Angly FE., Heath AC., Rohwer F., Gordon JI. 2010. Viruses in the faecal microbiota of monozygotic twins and their mothers. Nature 466:334-338. DOI: $\underline{10.1038 / \text { nature09199. }}$

Richter DC., Ott F., Auch AF., Schmid R., Huson DH. 2008. MetaSim-A sequencing simulator for genomics and metagenomics. PLoS ONE 3:e3373. DOI: 10.1371/journal.pone.0003373.

Rihtman B., Meaden S., Clokie MRJ., Koskella B., Millard AD. 2016. Assessing Illumina technology for the high-throughput sequencing of bacteriophage genomes. PeerJ 4:e2055. DOI: $10.7717 /$ peerj.2055.

Rosario K., Schenck RO., Harbeitner RC., Lawler SN., Breitbart M. 2015. Novel circular singlestranded DNA viruses identified in marine invertebrates reveal high sequence diversity and consistent predicted intrinsic disorder patterns within putative structural proteins. Frontiers in Microbiology 6:696. DOI: 10.3389/fmicb.2015.00696.

Rose R., Constantinides B., Tapinos A., Robertson DL., Prosperi M. 2016. Challenges in the analysis of viral metagenomes. Virus Evolution 2:vew022. DOI: 10.1093/ve/vew022.

Roux S, Adriaenssens EM, Dutilh BE, Koonin EV, Kropinski AM, Krupovic M, Kuhn JH, Lavigne R, Brister JR, Varsani A, Amid C, Aziz RK, Bordenstein SR, Bork P, Breitbart M, Cochrane GR, Daly RA, Desnues C, Duhaime MB, Emerson JB, Enault F, Fuhrman JA, Hingamp P, Hugenholtz P, Hurwitz BL, Ivanova NN, Labonté JM, Lee K-B, Malmstrom RR, Martinez-Garcia M, Mizrachi IK, Ogata H, Páez-Espino D, Petit M-A, 
603

604

605

606

607

608

609

610

611

612

613

614

615

616

617

618

619

620

621

622

623

624

625

626

627

628

629

630

631

632

633

Putonti C, Rattei T, Reyes A, Rodriguez-Valera F, Rosario K, Schriml L, Schulz F, Steward GF, Sullivan MB, Sunagawa S, Suttle CA, Temperton B, Tringe SG, Thurber RV, Webster NS, Whiteson KL, Wilhelm SW, Wommack KE, Woyke T, Wrighton KC, Yilmaz P, Yoshida T, Young MJ, Yutin N, Allen LZ, Kyrpides NC, Eloe-Fadrosh EA. 2018. Minimum Information about an Uncultivated Virus Genome (MIUViG). Nature Biotechnology 37:29-37. DOI: 10.1038/nbt.4306.

Roux S., Enault F., Hurwitz BL., Sullivan MB. 2015. VirSorter: mining viral signal from microbial genomic data. PeerJ 3:e985. DOI: 10.7717/peerj.985.

Roux S., Enault F., Robin A., Ravet V., Personnic S., Theil S., Colombet J., Sime-Ngando T., Debroas D. 2012. Assessing the diversity and specificity of two freshwater viral communities through metagenomics. PloS One 7:e33641. DOI:

10.1371/journal.pone.0033641.

Roux S., Tournayre J., Mahul A., Debroas D., Enault F. 2014. Metavir 2: new tools for viral metagenome comparison and assembled virome analysis. BMC Bioinformatics 15:76. DOI: $10.1186 / 1471-2105-15-76$.

Sangwan N., Xia F., Gilbert JA. 2016. Recovering complete and draft population genomes from metagenome datasets. Microbiome 4:8. DOI: 10.1186/s40168-016-0154-5.

Santiago-Rodriguez TM., Ly M., Bonilla N., Pride DT. 2015. The human urine virome in association with urinary tract infections. Frontiers in Microbiology 6:14. DOI: 10.3389/fmicb.2015.00014.

Sharon I., Banfield JF. 2013. Microbiology. Genomes from metagenomics. Science (New York, N.Y.) 342:1057-1058. DOI: 10.1126/science.1247023.

Sible E., Cooper A., Malki K., Bruder K., Watkins SC., Fofanov Y., Putonti C. 2015. Survey of viral populations within Lake Michigan nearshore waters at four Chicago area beaches. Data in Brief 5:9-12. DOI: 10.1016/i.dib.2015.08.001.

Simmonds P., Adams MJ., Benkő M., Breitbart M., Brister JR., Carstens EB., Davison AJ., Delwart E., Gorbalenya AE., Harrach B., Hull R., King AMQ., Koonin EV., Krupovic M., Kuhn JH., Lefkowitz EJ., Nibert ML., Orton R., Roossinck MJ., Sabanadzovic S., Sullivan MB., Suttle CA., Tesh RB., van der Vlugt RA., Varsani A., Zerbini FM. 2017. Virus taxonomy in the age of metagenomics: Consensus statement. Nature Reviews Microbiology 15:161-168. DOI: 10.1038/nrmicro.2016.177. 
634 Skvortsov T., de Leeuwe C., Quinn JP., McGrath JW., Allen CCR., McElarney Y., Watson C., 635 Arkhipova K., Lavigne R., Kulakov LA. 2016. Metagenomic Characterisation of the 636 Viral Community of Lough Neagh, the Largest Freshwater Lake in Ireland. PloS One 637 11:e0150361. DOI: 10.1371/journal.pone.0150361.

638

639

640

641

642

643

644

645

646

647

648

649

650

651

652

653

654

655

656

657

658

659

660

661

662

663

Smits SL., Bodewes R., Ruiz-Gonzalez A., Baumgärtner W., Koopmans MP., Osterhaus ADME., Schürch AC. 2014. Assembly of viral genomes from metagenomes. Frontiers in Microbiology 5:714. DOI: 10.3389/fmicb.2014.00714.

Smits SL., Bodewes R., Ruiz-González A., Baumgärtner W., Koopmans MP., Osterhaus ADME., Schürch AC. 2015. Recovering full-length viral genomes from metagenomes. Frontiers in Microbiology 6:1069. DOI: 10.3389/fmicb.2015.01069.

Stachler E., Kelty C., Sivaganesan M., Li X., Bibby K., Shanks OC. 2017. Quantitative CrAssphage PCR assays for human fecal pollution measurement. Environmental Science \& Technology 51:9146-9154. DOI: 10.1021/acs.est.7b02703.

Thannesberger J., Hellinger H-J., Klymiuk I., Kastner M-T., Rieder FJJ., Schneider M., Fister S., Lion T., Kosulin K., Laengle J., Bergmann M., Rattei T., Steininger C. 2017. Viruses comprise an extensive pool of mobile genetic elements in eukaryote cell cultures and human clinical samples. The FASEB Journal 31:1987-2000. DOI:

10.1096/fj.201601168R.

Tithi SS, Aylward FO, Jensen RV, Zhang L. 2018. FastViromeExplorer: a pipeline for virus and phage identification and abundance profiling in metagenomics data. PeerJ 6:e4227. DOI: $10.7717 /$ peerj.4227.

Vigil-Stenman T., Ininbergs K., Bergman B., Ekman M. 2017. High abundance and expression of transposases in bacteria from the Baltic Sea. The ISME journal 11:2611-2623. DOI: 10.1038/ismej.2017.114.

Voorhies AA., Eisenlord SD., Marcus DN., Duhaime MB., Biddanda BA., Cavalcoli JD., Dick GJ. 2016. Ecological and genetic interactions between cyanobacteria and viruses in a low-oxygen mat community inferred through metagenomics and metatranscriptomics. Environmental Microbiology 18:358-371. DOI: 10.1111/1462-2920.12756.

Wan Y., Renner DW., Albert I., Szpara ML. 2015. VirAmp: a galaxy-based viral genome assembly pipeline. GigaScience 4:19. DOI: 10.1186/s13742-015-0060-y. 
664 Watkins SC., Kuehnle N., Ruggeri CA., Malki K., Bruder K., Elayyan J., Damisch K., Vahora 665 N., O’Malley P., Ruggles-Sage B., Romer Z., Putonti C. 2016. Assessment of a 666 667 metaviromic dataset generated from nearshore Lake Michigan. Marine and Freshwater Research 67:1700. DOI: 10.1071/MF15172.

668 669

670

671

672

673

674

675

676

677

678

679

680

681

682

683

684

685

686

687

688

689

690

691

692

693

694

Watkins SC., Sible E., Putonti C. 2018. Pseudomonas PB1-Like Phages: Whole Genomes from Metagenomes Offer Insight into an Abundant Group of Bacteriophages. Viruses 10. DOI: 10.3390/v10060331.

Wommack KE., Bhavsar J., Polson SW., Chen J., Dumas M., Srinivasiah S., Furman M., Jamindar S., Nasko DJ. 2012. VIROME: a standard operating procedure for analysis of viral metagenome sequences. Standards in Genomic Sciences 6:427-439. DOI: 10.4056/sigs.2945050.

Yamashita A., Sekizuka T., Kuroda M. 2016. VirusTAP: Viral Genome-Targeted Assembly Pipeline. Frontiers in Microbiology 7:32. DOI: 10.3389/fmicb.2016.00032.

Yooseph S., Sutton G., Rusch DB., Halpern AL., Williamson SJ., Remington K., Eisen JA., Heidelberg KB., Manning G., Li W., Jaroszewski L., Cieplak P., Miller CS., Li H., Mashiyama ST., Joachimiak MP., van Belle C., Chandonia J-M., Soergel DA., Zhai Y., Natarajan K., Lee S., Raphael BJ., Bafna V., Friedman R., Brenner SE., Godzik A., Eisenberg D., Dixon JE., Taylor SS., Strausberg RL., Frazier M., Venter JC. 2007. The Sorcerer II Global Ocean Sampling expedition: expanding the universe of protein families. PLoS biology 5:e16. DOI: 10.1371/journal.pbio.0050016.

Zablocki O., van Zyl L., Adriaenssens EM., Rubagotti E., Tuffin M., Cary SC., Cowan D. 2014. High-level diversity of tailed phages, eukaryote-associated viruses, and virophage-like elements in the metaviromes of antarctic soils. Applied and Environmental Microbiology 80:6888-6897. DOI: 10.1128/AEM.01525-14.

Zeigler Allen L., McCrow JP., Ininbergs K., Dupont CL., Badger JH., Hoffman JM., Ekman M., Allen AE., Bergman B., Venter JC. 2017. The Baltic Sea Virome: Diversity and Transcriptional Activity of DNA and RNA Viruses. mSystems 2. DOI: 10.1128/mSystems.00125-16.

Zhang W., Zhou J., Liu T., Yu Y., Pan Y., Yan S., Wang Y. 2015. Four novel algal virus genomes discovered from Yellowstone Lake metagenomes. Scientific Reports 5:15131. DOI: $\underline{10.1038 / \text { srep } 15131 .}$ 
695 Zhao G., Wu G., Lim ES., Droit L., Krishnamurthy S., Barouch DH., Virgin HW., Wang D.

696 2017. VirusSeeker, a computational pipeline for virus discovery and virome composition 697 analysis. Virology 503:21-30. DOI: 10.1016/j.virol.2017.01.005.

698

699

700 Table Legends

701 Table 1. Software integrated into the virMine pipeline.

702 Table 2. Complex community microbiomes examined for virMine proof-of-concept study.

703 Table 3. BLAST homology for longer (> $5000 \mathrm{bp}$ ) contigs predicted as viral. *Indicates BLAST

704 homologies to annotated prophage regions.

705 Table 4. Viral genome sequences identified by virMine from the Lough Neagh virome (Skvortsov 706 et al. 2016). * Contig also predicted as viral by VirSorter (Roux et al. 2015).

707

708

709 Supplemental File Legends

710 Supplemental File 1. Metagenomic data sets examined.

711 Supplemental File 2. virMine results for synthetic communities and three metagenomic data 712 sets examined.

713 Supplemental File 3. BLAST queries to the $\mathrm{nr} / \mathrm{nt}$ database of the sequences uniquely identified 714 by virMine and VirSorter. 


\section{Figure 1}

Overview of virMine pipeline.

Tools integrated into the pipeline are listed in red. The sequences for viral contigs predicted with high confidence ("viral_contigs") and putative viral contigs ("unkn_contigs") are written to file. 
(1)

User supplies a raw

single-end and/or

paired-end fastq file(s)

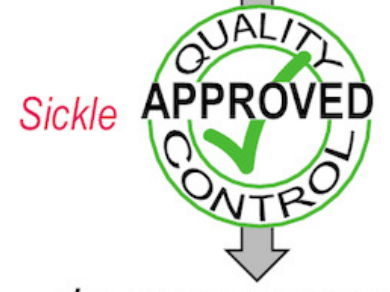

de novo assembly

User supplies

a fasta format assembly file

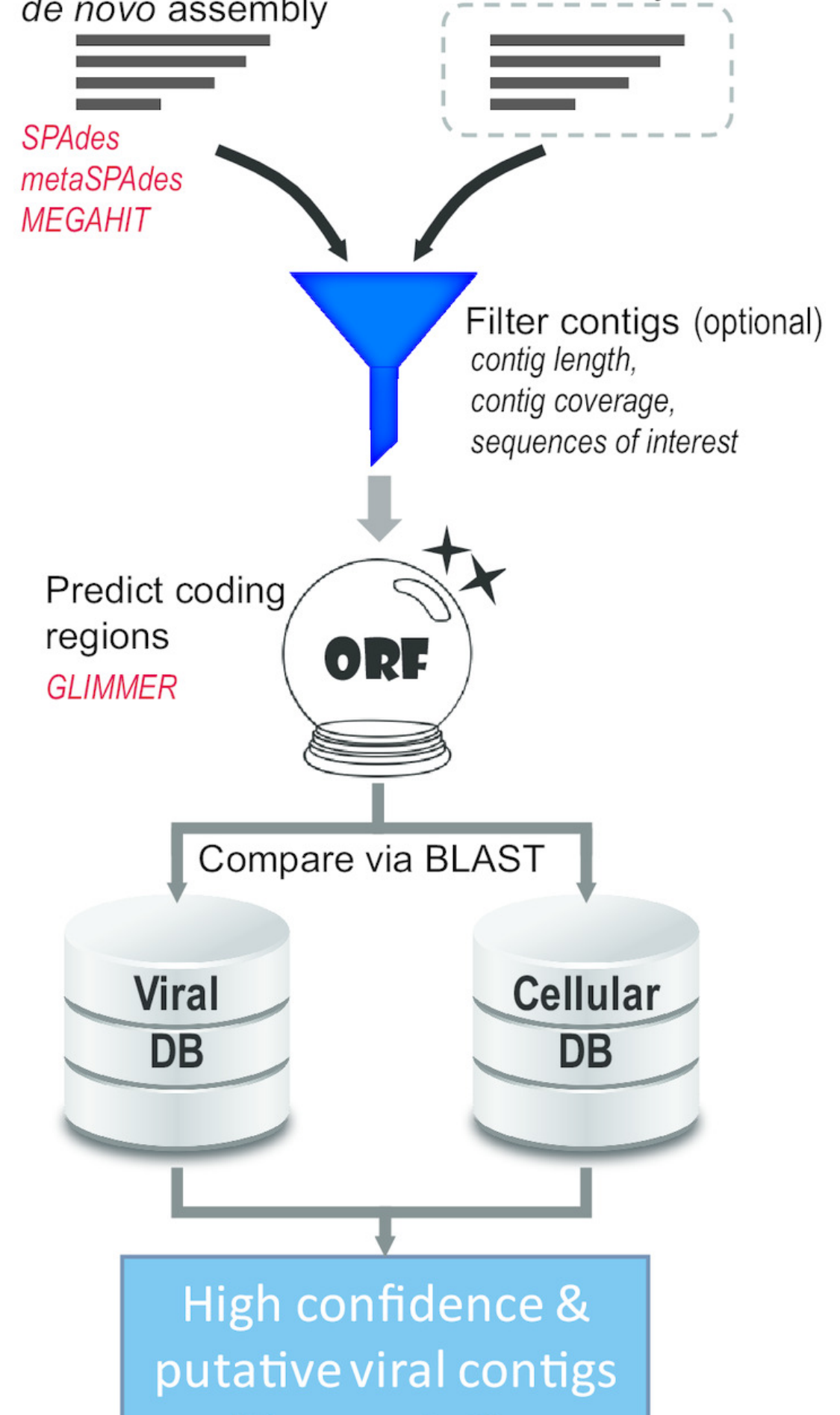

Peer reviewing PDF | (2018:11:33157:1:1:NEW 22 Feb 2019) 


\section{Figure 2 (on next page)}

Number of contigs assembled for each of the synthetic data sets predicted as viral (black bars) or of unknown origin (gray bars).

The $N_{50}$ score of the assembled contigs in each group is indicated within the corresponding bars. 
$5 \quad$ PeerJ

口 viral

unknown

4

o 3

ज

ज़ ज्ञ

ن 2

\#

2

1

0

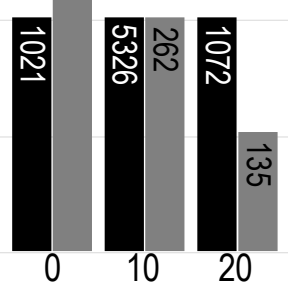

엄
$\infty$
œ

$\overrightarrow{8}$

जे

viewed

Data Set (\% reads from PB1 genome) 
Figure 3 (on next page)

Coverage of crAssphage by contigs predicted by virMine as viral or unknown. 


Coverage
crAssphage


Figure 4 (on next page)

Viral species most frequently detected within the Lake Michigan data sets. 
PeerJ Ralstonia phage RSK1

Burkholderia phage $\mathrm{BcepB} 1 \mathrm{~A}$

Cellulophaga phage phi38:1

Nonlabens phage P12024S

Puniceispirillum phage HMO-2011

Burkholderia phage BcepNazgul

Acanthamoeba polyphaga mimivirus

Nonlabens phage P12024L

Rhizobium phage vB_RleM_PPF1

Mesorhizobium phage vB_MloP_Lo5R7ANS

Pandoravirus salinus

Pandoravirus dulcis

Vibrio phage X29

Burkholderia phage $\mathrm{AH} 2$

Burkholderia virus phiE125

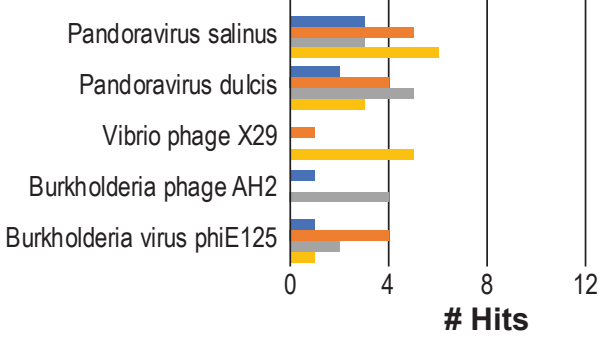

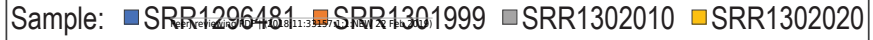




\section{Table 1 (on next page)}

Software integrated into the virMine pipeline. 
1 Table 1. Software integrated into the virMine pipeline.

\begin{tabular}{|l|l|l|l|}
\hline Tool & Version & Task & Citation \\
\hline Sickle & 1.33 & $\begin{array}{l}\text { Read } \\
\text { trimming }\end{array}$ & https://github.com/najoshi/sickle \\
\hline SPAdes & 3.10 .1 & Assembly & Bankevich et al. 2012 \\
\hline metaSPAdes & 3.10 .1 & Assembly & Nurk et al. 2017 \\
\hline MEGAHIT & 1.1 .4 & Assembly & Li D et al. 2016 \\
\hline BBMap & 37.36 & Coverage & https://sourceforge.net/projects/bbmap/ \\
\hline GLIMMER & 3.02 & $\begin{array}{l}\text { Gene } \\
\text { prediction }\end{array}$ & Delcher et al. 1999 \\
\hline BLAST+ & 2.6 .0 & $\begin{array}{l}\text { Sequence } \\
\text { Analysis }\end{array}$ & ftp://ftp.ncbi.nlm.nih.gov/blast/executables/blast $+/$ \\
\hline
\end{tabular}

2

3 
Table 2 (on next page)

Complex community microbiomes examined for virMine proof-of-concept study. 
1 Table 2. Complex community microbiomes examined for virMine proof-of-concept study.

\begin{tabular}{|c|c|c|c|c|}
\hline Sample & Study Details & $\begin{array}{l}\text { Sequencing } \\
\text { Technology }\end{array}$ & \# samples & $\begin{array}{l}\text { \# reads } \\
\text { (millions) }\end{array}$ \\
\hline Synthetic & $\begin{array}{l}P . \text { aeruginosa and } \\
\text { Pseudomonas phage } \mathrm{PB} 1 \\
\text { genomes }\end{array}$ & N/A & 22 & 4.4 \\
\hline \multirow[t]{2}{*}{$\begin{array}{l}\text { Gut } \\
\text { Microbiomes }\end{array}$} & $\begin{array}{l}\text { A subset of faecal microbiota } \\
\text { of monozygot twins and their } \\
\text { mothers (Reyes et al. 2010) }\end{array}$ & $454 \mathrm{FLX}$ & 3 & 0.66 \\
\hline & $\begin{array}{l}\text { A subset of faecal samples } \\
\text { from } 124 \text { European individuals } \\
\text { (Qin et al. 2010) }\end{array}$ & $\begin{array}{l}\text { Illumina } \\
\text { Genome } \\
\text { Analyzer }\end{array}$ & 55 & 1141.33 \\
\hline $\begin{array}{l}\text { Urinary } \\
\text { Viromes }\end{array}$ & $\begin{array}{l}\text { UTI positive urine samples } \\
\text { (Santiago-Rodriguez et al. } \\
\text { 2015) }\end{array}$ & $\begin{array}{l}\text { Ion Torrent } \\
\text { PGM }\end{array}$ & 10 & 6.22 \\
\hline \multirow[t]{2}{*}{$\begin{array}{l}\text { Freshwater } \\
\text { Viromes }\end{array}$} & $\begin{array}{l}\text { A subset of samples from Lake } \\
\text { Michigan nearshore waters } \\
\text { (Sible et al. 2010) }\end{array}$ & $\begin{array}{l}\text { Illumina } \\
\text { MiSeq }\end{array}$ & 4 & 13.46 \\
\hline & $\begin{array}{l}\text { Viral community of Lough } \\
\text { Neagh (Skvortsov et al. 2016) }\end{array}$ & $\begin{array}{l}\text { Illumina } \\
\text { MiSeq }\end{array}$ & 1 & 4.60 \\
\hline
\end{tabular}




\section{Table 3 (on next page)}

BLAST homology for longer ( $>5000 \mathrm{bp}$ ) contigs predicted as viral.

*Indicates BLAST homologies to annotated prophage regions. 
1 Table 3. BLAST homology for longer (> $5000 \mathrm{bp}$ ) contigs predicted as viral. *Indicates BLAST

2 homologies to annotated prophage regions.

\begin{tabular}{|c|c|c|c|c|c|}
\hline SRA Run \# & BLAST hit & $\begin{array}{l}\text { Accession } \\
\#\end{array}$ & $\begin{array}{l}\text { Contig } \\
\text { Length } \\
\end{array}$ & $\begin{array}{l}\% \\
\text { ID }\end{array}$ & $\begin{array}{l}\% \\
\text { QC }\end{array}$ \\
\hline \multirow[b]{2}{*}{ MGM4568637 } & Cyanothece sp. PCC 7822 & CP002198 & 14157 & 73 & 0 \\
\hline & Choristoneura rosaceana entomopoxvirus 'L' & HF679133 & 11424 & 66 & 15 \\
\hline \multirow[b]{2}{*}{ MGM4568639 } & Erlichia canis strain YZ-1* & CP02479 & 12310 & 73 & 8 \\
\hline & Burkholderia sp. MSMB0856 & CP013427 & 5156 & 71 & 5 \\
\hline \multirow[b]{2}{*}{ MGM4568640 } & Clostridium taeniosporum strain $1 / \mathrm{k}$ & CP017253 & 7987 & 69 & 2 \\
\hline & Escherichia phage YDC107 2 & $\mathrm{CP} 025713$ & 5479 & 96 & 88 \\
\hline \multirow[b]{4}{*}{ MGM4568641 } & Enterococcus faecalis V583* & AE016830 & 16416 & 95 & 95 \\
\hline & Uncultured Mediterranean phage uvMED & AP013535 & 13087 & 79 & 1 \\
\hline & Turicibacter $\mathrm{sp} . \mathrm{H} 121$ & CP013476 & 7825 & 83 & 0 \\
\hline & Enterococcus faecalis strain L9* & CP018004 & 5086 & 99 & 100 \\
\hline \multirow[b]{2}{*}{ MGM4568642 } & Choristoneura rosaceana entomopoxvirus 'L' & HF679133 & 9301 & 66 & 27 \\
\hline & Protochlamydia naegleriophila PNK1 & LN879502 & 5312 & 83 & 1 \\
\hline \multirow[b]{2}{*}{ MGM4568645 } & Rickettsiales bacterium Ac37b* & CP009217 & 8302 & 66 & 11 \\
\hline & Rickettsiales bacterium Ac37b* & CP009217 & 8215 & 68 & 19 \\
\hline
\end{tabular}

3 


\section{Table 4 (on next page)}

Viral genome sequences identified by virMine from the Lough Neagh virome (Skvortsov et al. 2016).

* Contig also predicted as viral by VirSorter (Roux et al. 2015). 
1 Table 4. Viral genome sequences identified by virMine from the Lough Neagh virome (Skvortsov et al. 2016). * Contig also predicted

2 as viral by VirSorter (Roux et al. 2015).

\begin{tabular}{|c|c|c|c|c|c|c|c|}
\hline Contig & Length & \# CDS & Hit: Description & Accession & Query Cov & ID & Isolation Source \\
\hline contig 11 & 46867 & 71 & $\begin{array}{l}\text { Chromobacterium rhizoyzae } \\
\text { strain JP2-74 }\end{array}$ & CP031968.1 & 1 & 80 & rhizosphere \\
\hline contig 12 & 46702 & 74 & $\begin{array}{l}\text { Uncultured marine virus isolate } \\
\text { CBSM-242 }\end{array}$ & FJ640348.1 & 0 & 83 & $\begin{array}{l}\text { Chesapeake Bay } \\
\text { sediment }\end{array}$ \\
\hline contig_13 & 46245 & 60 & Bacteriophage $11 \mathrm{~b}$ & AJ842011.2 & 1 & 68 & Arctic sea ice \\
\hline contig_ 17 & 40578 & 56 & $\begin{array}{l}\text { Methylobacterium brachiatum } \\
\text { strain TX0642 }\end{array}$ & СР033231.1 & 6 & 67 & $\begin{array}{l}\text { Automobile air- } \\
\text { conditioning evaporator }\end{array}$ \\
\hline contig_18 & 40568 & 61 & Blastochloris sp. GI & AP018907.1 & 0 & 72 & Soda dam hot springs \\
\hline contig_2* & 70520 & 92 & $\begin{array}{l}\text { Uncultured virus } \\
\text { YBW_Contig_50752 }\end{array}$ & KU756933.1 & 1 & 72 & $\begin{array}{l}\text { North Sea Surface Water } \\
\text { Virome }\end{array}$ \\
\hline contig_ 5 & 56143 & 55 & Uncultured virus SERC 372681 & KU595468.1 & 2 & 73 & $\begin{array}{l}\text { Rhode River surface } \\
\text { water }\end{array}$ \\
\hline contig_6 & 55961 & 75 & $\begin{array}{l}\text { Polynucleobacter asymbioticus } \\
\text { strain MWH-RechtKol4 }\end{array}$ & CP015017.1 & 1 & 71 & freshwater \\
\hline contig 7 & 55939 & 77 & $\begin{array}{l}\text { Uncultured virus SERC Contig } \\
695464\end{array}$ & KU971113.1 & 0 & 76 & $\begin{array}{l}\text { Rhode River surface } \\
\text { water }\end{array}$ \\
\hline
\end{tabular}

